\title{
Patterns of phenotypic variation reveal substantial differentiation in sexual dimorphism of three Psammodromus (Squamata, Lacertidae) species
}

\author{
Luis M. San-Jose ${ }^{1,2,3,5}$, Virginia Gonzalez-Jimena ${ }^{2,3}$, Patrick S. Fitze ${ }^{1,2,3,4}$ \\ ${ }^{1}$ University of Lausanne, Department of Ecology and Evolution, Biophore, 1015 Lausanne, Switzerland \\ ${ }^{2}$ Museo Nacional de Ciencias Naturales (MNCN-CSIC), Department of Biodiversity and Evolutionary Biology, \\ José Gutiérrez Abascal 2, 28006 Madrid, Spain \\ ${ }^{3}$ Instituto Pirenaico de Ecología (IPE-CSIC), Nuestra Señora de la Victoria s/n, 20700 Jaca, Spain \\ ${ }^{4}$ Fundación Araid, Edificio Pignatelli, Paseo María Agustín 36, 50004 Zaragoza, Spain \\ ${ }^{5}$ E-mail: luis.sanjosegarcia@unil.ch
}

Key words: colouration, Psammodromus edwardsianus, Psammodromus hispanicus, Psammodromus occidentalis, sexual dimorphism

\begin{abstract}
The Spanish sand racer (Psammodromus hispanicus) has been recently split into three distinct species: $P$. hispanicus, $P$. edwardsianus, and $P$. occidentalis. Some morphological differences have been reported but there is as yet no description allowing unambiguous identification of the three species. Here, we describe differentiation in body measurements, scalation traits, and colour traits as well as in the degree of sexual dimorphism. Our results show that P. edwardsianus can be easily distinguished by the presence of a supralabial scale below the subocular scale, which is absent in the other two species. Psammodromus hispanicus and $P$. occidentalis can be distinguished by the number of femoral pores, throat scales and ocelli, and the relative width of the anal scale. The degree of sexual size dimorphism and sexual colour dimorphism substantially differs among species, suggesting that different scenarios of sexual and natural selection may exist for each species. Moreover, sexually selected traits (nuptial colouration, ocelli, and femoral pores) significantly differ among species, suggesting that visual and chemical communication may also differ among species. Such differences could prevent reproduction and gene flow at secondary contact zones, potentially reinforcing isolation and speciation within this group of lizards.
\end{abstract}

\section{Contents}

Introduction 181

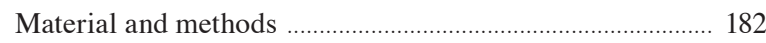

Population sampling and field measurements ............... 182

Body measures and scalation traits ................................. 185

Colour traits .................................................................. 185

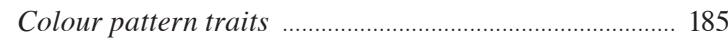

Statistical analysis ............................................................... 186

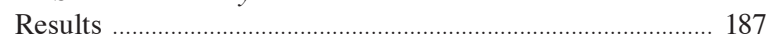

Differences among species ............................................. 187

Differences between northern and southern

populations of $\mathrm{P}$. edwardsianus ............................................ 188

Key for the three Psammodromus species ....................... 192

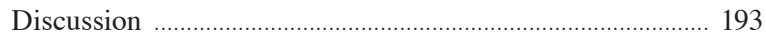

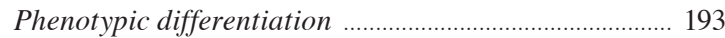

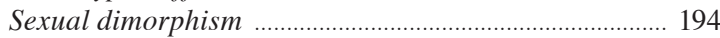

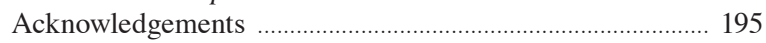

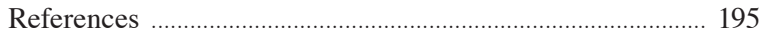

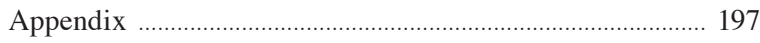

\section{Introduction}

The Spanish sand racer, Psammodromus hispanicus Fitzinger, 1826 (Squamata, Lacertidae), is a small ground-dwelling lizard that inhabits the Iberian Peninsula and the French Mediterranean coast. It lives in sandy open habitats scattered with small bushes that it uses as shelters (Blasco, 1974; Carrascal et al., 1989; Carretero and Llorente, 1991a). Early descriptions suggested the existence of two subspecies, $P$. hispanicus hispanicus (Fitzinger, 1826) on the Western Iberian Peninsula and P. hispanicus edwardsianus (Dugès, 1829) in the Eastern Iberian Peninsula and south of France (Boulenger, 1921; Hellmich, 1962; Perez-Mellado, 1998). Initial molecular studies provided evidence for important genetic differentiation between these two subspecies (Carranza et al., 2006). However, recent studies based on wider sampling and using both mitochondrial and nuclear data support the existence of three distinct species: P. edwardsianus (Dugès, 1829), P. hispanicus Fitzinger, 1826, and P. occidentalis Fitze et al., 2012 (see Fitze et al., 2011, 2012). Psammodromus edwardsianus inhabits the Eastern Iberian Peninsula and Southern France, and split 4.8 (1.5-8.7) million years ago (Mya) from P. hispanicus, which inhabits the centre of the Iberian Peninsula. Psammodromus occidentalis, inhabiting the Western Iberian 
Peninsula, diverged 8.3 (2.9-14.7) Mya from the ancestor of P. hispanicus and P. edwardsianus. Additionally, genetic differentiation between northern and southern populations has been found within P. edwardsianus and $P$. occidentalis, suggesting northern range expansions after the last glaciation. In contrast, no clear geographic structure has been found in P. hispanicus (Fitze et al., 2011).

To date, the few existing phenotypic studies on $P$. hispanicus focused on the description of the two subspecies suggested by Boulenger (1921) and, thus, only on the differences between western and eastern populations of Spanish sand racers. However, this west-east scenario yielded contradictory phenotypic descriptions. For instance, whereas some authors claimed that traits such as the number of femoral pores or supralabial scales differ between western and eastern populations, other authors reported no differentiation (Boulenger, 1921; Blasco, 1974; Perez-Mellado, 1998). The existence of a third genetically distinct group in the centre of the Iberian Peninsula as recently demonstrated by Fitze et al. (2011) likely underlies these contradictory findings. Fitze et al. $(2011,2012)$ present the formal description of the three species, provided a preliminary and succinct phenotypic description of $P$. edwardsianus, P. hispanicus, and P. occidentalis. Yet, differences among species in important phenotypic characters such as colouration and colour patterns as well as in the degree of sexual dimorphism in colour traits, body measurements, and scalation traits have not been studied so far. Differentiation in colour traits and sexual dimorphism may occur rapidly during spe- ciation (Lande, 1981). Interspecific differences in sexual dimorphism may indicate differences in the intensity of sexual and natural selection (Anderson, 1994; Stuart-Fox and Ord, 2004). Similarly, variation between sister species in colour traits may indicate that species are subjected to distinct selective pressures for example, owing to differences in ecological conditions (Stuart-Fox et al., 2003; Stuart-Fox and Ord, 2004).

In the present study we studied phenotypic differentiation among the three Spanish sand racer species, combining the phenotypic traits studied in Fitze et al. (2011) with sixteen new external traits concerning colouration and colour pattern. We further investigated which phenotypic traits are sexually dimorphic and whether the degree of sexual dimorphism differs among species. We also tested if the genetic differences found between northern and southern populations of $P$. edwardsianus and P. occidentalis are associated with phenotypic differences. Finally, we developed a dichotomous key to distinguish between the three species, which is particularly useful for field classification and conservation purposes.

\section{Material and methods}

\section{Population sampling and field measurements}

In spring 2006, we sampled 21 Spanish populations that had been previously delineated using genetic markers as Psammodromus hispanicus, P. edwardsianus (northern and southern clade), and $P$. occidentalis

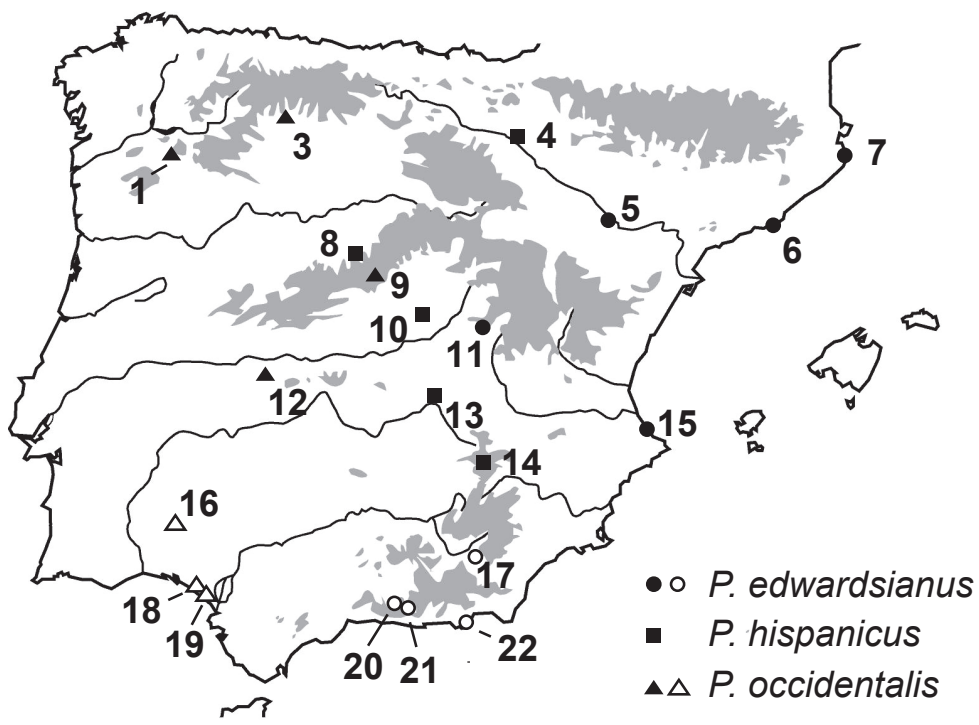

Fig. 1. Locations sampled of the three Spanish sand racer species (referenced in Table S1) Northern ( $\bullet$ ) and southern (O) populations of Psammodromus edwardsianus and northern $(\mathbf{\Delta})$ and southern $(\triangle)$ populations of $P$. occidentalis are also indicated. 
Table 1. Summary of measured variables. Numbers in brackets correspond to numbers in Fig. 2. Variables directly used in the statistical analyses are plotted in bold, whereas variables not used in the statistical analyses, but used to derive other variables (e.g. shape descriptors) or principal components (PC) are italicized.

Variable Description (unit)

a. Body measures and scalation

SVL [1]

Total length

SVL ratio

Body mass

Snout width [2]

Snout length [3]

Snout shape

Head length [4]

Head width [5]

Head shape

Anal scale width [6]

Relative anal scale width

Femoral pores [7]

Ventral scales [8]

Subocular scales [9]

Throat scales [10]

Collar scales [11]
Snout to vent length $(\mathrm{mm})$ measured on the alive animal

Snout to tail tip length $(\mathrm{mm})$ measured on the alive animal

Total length / SVL

Lizard weight $(\mathrm{g})$

Distance $(\mathrm{mm})$ between the left and right foremost intersection point of the first supraocular and the first supracilliar scale

Distance $(\mathrm{mm})$ between the borders of the outermost left and right supraocular scales (located behind the eyes)

Degree of snout sharpness. Snout length / snout width

Distance $(\mathrm{mm})$ between the tip of the snout and the occipital edge

Distance $(\mathrm{mm})$ between the borders of the last left and right supraocular scale

Degree of head sharpness. Head width / head length

Distance $(\mathrm{mm})$ between the posterior borders of the anal scale

Anal scale width / SVL

Mean number of right and left femoral pores

Number of transverse ventral scale rows

Number of supralabial scales below subocular scale

Number of throat scales

Number well-differentiated collar scales

b. Colour traits

Anal scale colouration [12]

First ventral scale row colour [13]

Mid ventral scale row colour [13]

Last ventral scale row colour [13]

Ventral scale colour

Ventral colouration PC1, PC2, PC3

Neck colour [14]

Background colour [15]

Black transverse line colour [16]

White longitudinal line colour [17]

Dorsal colour PC1, PC2 mean hue $\left({ }^{\circ}\right)$, mean saturation $(\%)$, and mean brightness $(\%)$ measured in four quadrants of the anal scale

mean hue $\left({ }^{\circ}\right)$, mean saturation $(\%)$, and mean brightness $(\%)$ of the 4 scales of the first transverse ventral scale row

mean hue $\left({ }^{\circ}\right)$, mean saturation (\%), and mean brightness (\%) of the 4 scales of the mid transverse ventral scale row

mean hue $\left({ }^{\circ}\right)$, mean saturation $(\%)$, and mean brightness (\%) of the 4 scales of scales of the last transverse ventral scale row

mean hue $\left({ }^{\circ}\right)$, mean saturation $(\%)$, and mean brightness $(\%)$ of the anterior, middle and posterior ventral scales

principal components of anal scale and all ventral scale HSB values

mean hue $\left({ }^{\circ}\right)$, mean saturation $(\%)$, and mean brightness $(\%)$ of the first 8 scales of the left and right outermost longitudinal lines

mean hue $\left(^{\circ}\right)$, mean saturation $(\%)$, and mean brightness $(\%)$ of the brown background colouration

mean hue $\left({ }^{\circ}\right)$, mean saturation $(\%)$, and mean brightness $(\%)$ of the central scale of the first 5 black dorsal transverse lines

mean hue $\left({ }^{\circ}\right)$, mean saturation $(\%)$, and mean brightness $(\%)$ of the central scale of the first 5 white dorsal transverse lines

principal components of the HSB values of the dorsal black transverse lines and white longitudinal lines

c. Colour pattern traits

Dorsal pattern index

Proportion of black colouration

Proportion of white colouration

Dorsal line thickness [18]

Nuptial colouration

Number of ocelli [19]
See Methods and S - Figure 1 of the Supporting information for further details

Percentage of dorsal black colouration (further details see methods)

Percentage of dorsal white colouration (further details see methods)

Mean number of longitudinal scale rows forming the longitudinal lines

Extent of the green nuptial colouration along the lizard's body (further details see methods)

Mean number of right and left hand sided ocelli 

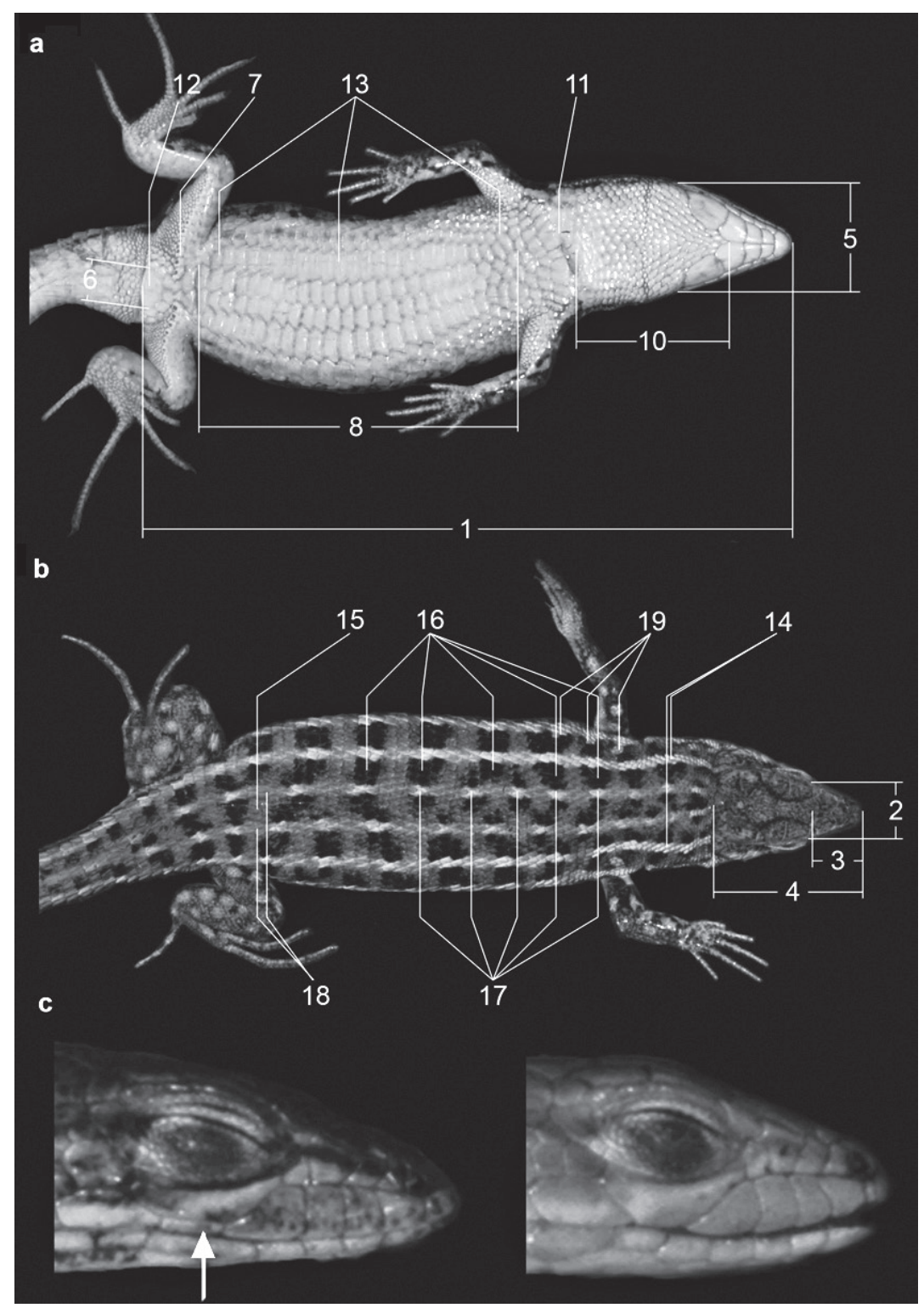

Fig. 2. Phenotypic measurements taken on Spanish sand racers. Numbers correspond to the traits summarized in Table 1. a. Ventral view of a lizard. b. Dorsal view of a lizard. c. Head detail showing the absence of a scale under the subocular scale (on the right; $P$. hispanicus and $P$. occidentalis) and the presence of a scale under the subocular scale (on the left; P. edwardsianus). (northern and southern clade). We captured a total of 211 adult lizards from these populations (Fig. 1, Table S1; for further details see Fitze et al., 2011). Genetic markers indicated that none of the species occurred in sympatry in the sampled populations (Fitze et al., 2011) and no differences in the latitude and altitude of the sampled populations existed between species (all $P$ $>0.16)$. Immediately after capture, we took a standardized photograph of the belly, back, and flanks of every lizard following Fitze and Richner (2002). Lizards were carefully placed into an opaque box filled with foam material. A photographic filter lens (Hoya UV- filter) was slid over the lizards to immobilize them. The box was placed in a standard position inside a larger opaque photographic chamber that maintained a fixed distance $(40 \mathrm{~cm})$ to a digital camera (Nikon D70S with a $105 \mathrm{~mm} \mathrm{f/2.8} \mathrm{Nikkor} \mathrm{objective).} \mathrm{Light}$ was provided by two flashes (Nikon SB-600) fixed at both sizes of the chamber at an angle of $13^{\circ}$ to the optical axis. Standard white patches $(10 \times 5 \mathrm{~mm}$, Kodak Colour Control Patches, red $=255$, green $=255$, blue $=$ 255) were fixed on each side of the filter lens for light calibration. No difference in light exposure was detected $(P>0.5)$. 


\section{Body measures and scalation traits}

Snout-to-vent length (SVL), total length (both measured with a ruler to the nearest $1 \mathrm{~mm}$ ), number of femoral pores, and body mass (to the nearest $1 \mathrm{mg}$ ) were determined in the field. Head and snout shape and the relative anal scale width were measured by importing the photographs into IMAGEJ program (National Institute of Science, USA) (Table 1a, Fig. 2). The number of ventral scale rows, the number of throat scale rows, the number of collar scales, and the presence/absence of a supralabial scale under the subocular scale were determined from the photographs (Table 1a, Fig. 2).

\section{Colour traits}

We used Adobe Photoshop 7.0 (Adobe Systems Inc., San Jose, California, USA) to calculate hue, saturation, and brightness (hereafter referred to as HSB) of different ventral and dorsal colour traits (Table 1b). We measured colour of the anal scale and ventral scales (Fig. 2a [12, 13]). The anal scale was divided into four quadrants referenced by the anal scale's longitudinal and transversal axes. In each quadrant, we measured mean HSB values of the $10 \times 10$ pixel area closest to the intersection using the average filter of Adobe Photoshop ${ }^{\circledR}$. Ventral scale colouration corresponds to the mean HSB values measured on the first, middle, and last transverse ventral scale rows. HSB values were measured from $10 \times 10$ pixel areas located in the middle of each of the four central scales in each row and the average per row was used in the analysis.

Dorsal colouration was characterized using four variables (Table 1b): neck colour, background colour, black transverse line colour, and white longitudinal line colour. Neck colour corresponds to the average HSB values measured on the left and right outermost, green-yellow longitudinal lines (Fig. 2b [14]). Average HSB values of a $6 \times 6$ pixel area were measured on the first eight scales of each longitudinal line and used to derive the average HSB values per line. Background colour measured the dominant brown colouration. Specifically, we measured mean HSB values of an $8 \times 8$ pixel area located between the black transversal line located between the hind legs and the subsequent black transversal line located closer towards the lizard's head (Fig. 2b [15]). Starting from the anterior legs and moving towards the hind legs, we measured the colour of the first five black transverse lines and white intersection points (colour of the white longitudinal lines; Fig. 2b $[16,17])$. We measured mean HSB values of an
$8 \times 8$ pixel area in the middle of each dark transverse line and intersection point. Means of the five black transverse lines and white intersection point measurements were used for the analyses.

\section{Colour pattern traits}

We distinguished four colour pattern traits (Table 1c). The dorsal pattern was classified with an index (dorsal pattern index) ranging from 0 to 7.5 and based on the presence, form (continuous, broken or spotted), and thickness (number of scale rows) of the black transverse lines as well as on the presence and form (continuous or dotted) of the whitish longitudinal lines (Fig. S2). For example, the dorsal pattern design in Fig. $2 \mathrm{~b}$ has an index score of 5.75. It shows continuous external longitudinal lines $(+1)$, dotted internal longitudinal lines (+0.75), and broken black transverse lines (+2) formed by two scale rows (+2). Additionally, we measured the thickness of the internal white longitudinal lines by counting on a standard position the number of transverse scale rows forming each line (Fig. 2b [18]). Mean number of scales of left and right lines was used for the analyses.

We measured the proportion of black and white colouration present on the lizards' back. We first selected a standard dorsal area between the hind and forelegs and between the outermost longitudinal lines. Within this area, we selected and calculated the number of black pixels using as black reference the mean HSB values measured on the black transverse lines (Table 1 [16]). The same procedure was used to calculate the number of white pixels but using as reference the mean HSB values of the white transverse lines (Table 1 [16]). Finally, we calculated the proportion of black and white colouration by dividing the counted black and white pixels by the number of pixels within the standard dorsal area.

The extent of the green nuptial colouration was measured using a nuptial colouration index (Fitze et al., 2011) considering the presence (1)/absence (0) of green colouration on the head, neck, belly, supralabial scales, and dorsal skin. When lizards showed dorsal nuptial colouration, we additionally added 0.5 for every coloured longitudinal line ( $N=4$ longitudinal lines) if colour did not reach the middle of the body and one point for every longitudinal line if colour extended further than the middle of the body. Thus, the maximum score was 9. We also counted the number of ocelli on left and right sides and used the mean for the analyses (Table 1b, Fig. 2b [19]). 


\section{Statistical analysis}

Statistical analyses were conducted using R 2.7.0 (R development core team, Vienna, Austria). Two repeated measurements taken on 12 lizards showed high repeatability of the variables (mean $r$ of all variables \pm $\mathrm{SE}=0.79 \pm 0.03$. Lowest repeatability was found for the number of throat scales: $F_{10,11} \geq 4.13, P \leq 0.014, r \geq$ 0.61; Lessells and Boag, 1987).

Prior to analysing differences between species, we ran separate principal component analyses (PCA) on ventral and dorsal colour traits because they were highly correlated within trait sets (Table 1). For subsequent analyses, we retained PC axes with eigenvalues greater than one (Quinn and Keough, 2002).

To investigate differences between species, we fitted a permutational MANOVA (PERM-MANOVA; Adonis function, Vegan package) based on Euclidean distances and 9999 permutations (Anderson, 2001; McArdle and Anderson, 2001). To correct for scale differences, we standardized all variables (including the derived PCs) by dividing mean-centred observations by the standard deviation of each variable (Quinn and Keough, 2002). In P. edwardsianus, differences between southern and northern populations were also tested using a similar PERM-MANOVA. Differences between northern and southern populations of $P$. oc- cidentalis could not be tested due to the low sample size $(\mathrm{N}=5)$ in southern populations. We derived linear discriminant functions (LDF) to assess the relative importance of each variable for species differentiation and for differentiation between northern and southern population of $P$. edwardsianus. We ran univariate ANOVAs to specifically investigate which traits differed among species and between northern and southern populations of $P$. edwardsianus (Quinn and Keough, 2002).

To test for differences between species in sexual dimorphism, we included sex and its interaction with species in the PERM-MANOVA and ANOVA models. We controlled for non-independence of animals captured in the same population and for interpopulation variation by including population as a factor nested within species. For brevity, population effects are not shown. Models were simplified by backward elimination of the non-significant terms. ANOVA assumptions of normality and homoscedasticity and PERMMANOVA assumption of homogeneity of multivariate dispersion were verified and log and power transformations were applied when necessary. Statistical significance was set at $\alpha=0.05$ and adjusted after multiple testing following Hochberg (1988).

To provide a method to distinguish the species under field conditions, we additionally derived LDF on

\section{a. Males}

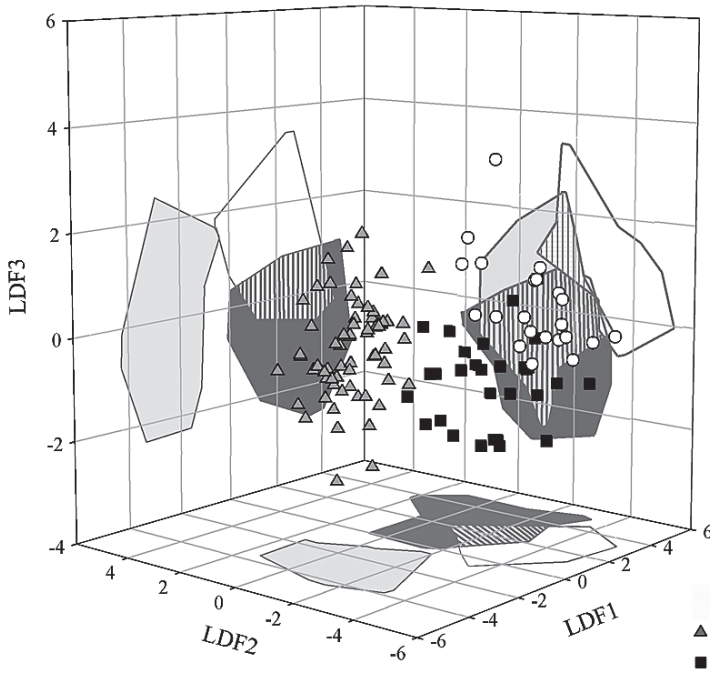

a. Females

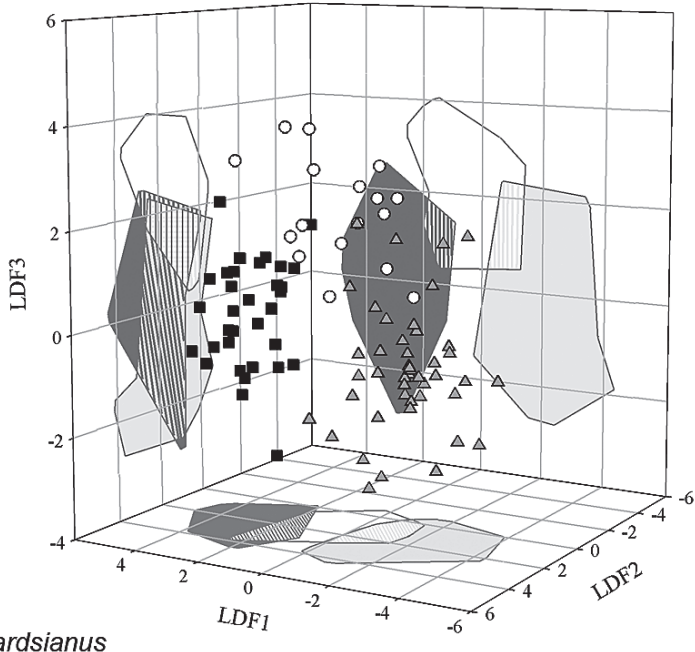

$\Delta P$. edwardsianus

- P. hispanicus

- P. occidentalis

Fig. 3. Three-dimensional plot of the first three LDF yielded by the discriminant analysis on a. males and b. females of $P$. $e d w a r d$ sianus, P. hispanicus, and P. occidentalis. The area for P. hispanicus (dark grey), P. edwardsianus (light grey), and P. occidentalis (clear area) are plotted on each two-dimensional panel. 
traits that are easy to measure in the field (femoral pores, throat scales, number of ocelli, and the relative anal scale width). Validation of species classifications was accomplished with leave-one-out cross-validation methods using the proportion of individuals sampled per species as prior probabilities (Venables and Ripley, 1999).

\section{Results}

Three PCs explained $88 \%$ of the variance in ventral and anal scale colouration. Ventral colouration PC1 mainly reflected the hue of ventral and anal scales whereas PC2 mainly reflected brightness and PC3, saturation. For dorsal colouration, two PCs explained $72.5 \%$ of the variance (Table S3). Dorsal colouration PC1 mainly reflected saturation and brightness of the black transverse lines and brightness of the white longitudinal lines whereas PC2 mainly reflected hue and saturation of the white longitudinal lines.

\section{Differences among species}

A PERM-MANOVA including all measured traits (variables indicated in bold in Table 1) showed statistically significant differences among the three Psammodromus species $\left(F_{2,182}=29.83, P<0.001\right)$. Post-hoc tests showed that there were significant differences between all three species pairs (all contrasts $t_{182} \geq 2.79$, $P<0.001)$. There were significant differences between sexes $\left(F_{1,182}=21.87, P<0.001\right)$ and the interaction between species and sex was also significant $\left(F_{2,182}=\right.$ $3.14, P<0.001)$.

Discriminant analyses yielded five LDF that successfully discriminated between species (Fig. 3). The presence/absence of a supralabial scale below the subocular scale (Fig. 2c) distinguished P. edwardsianus (present) from both $P$. hispanicus and P. occidentalis (absent) in $100 \%$ of the cases. Given the lack of variance, this trait could not be included in the discriminant analyses. LDF1 explained 55\% of the variance and mainly reflected neck hue and saturation, the extent of the nuptial colouration, and the number of femoral pores and throat scales (Table S4). This function separated $P$. edwardsianus males from $P$. hispanicus and $P$. occidentalis males (Fig. 3a). LDF1 also separated $P$. edwardsianus females from $P$. hispanicus females whereas $P$. occidentalis females occupied an intermediate position (Fig. 3b). LDF2 explained $31 \%$ of the variance and reflected SVL, the number of ven- tral scales, ventral colouration PC3, and relative anal scale width (Table S4). LDF2 separated $P$. occidentalis males from $P$. hispanicus males and males and females of all species (most males and females had negative and positive LDF2 scores, respectively; Fig. 3). LDF3, which explained $7.1 \%$ of the variance, separated $P$. occidentalis males and females from the other species. This function reflected the number of ocelli and ventral scales, the dorsal colouration PC2, and the proportion of white colouration. The remaining two LDFs only explained $6 \%$ and $1 \%$ of the variance, respectively (Table S4).

Univariate ANOVAs showed significant differences between species in body measures, scalation, colouration, and colour pattern (Table 2-3). All species differed significantly in the number of femoral pores and throat scales, which were higher in P. edwardsianus, intermediate in P. occidentalis, and lowest in P. hispanicus (see contrasts in Table 2). In all species, females showed a lower number of femoral pores than males, but no sex differences existed in the number of throat scales. Psammodromus edwardsianus showed a smaller SVL than P. hispanicus and P. occidentalis, which showed no significant differences between them. In all species, males were significantly smaller than females. SVL ratio (Table 1a) was significantly greater in $P$. edwardsianus than in P. occidentalis, whereas only a marginal trend was found between $P$. edwardsianus and $P$. hispanicus. No significant differences in SVL existed between $P$. occidentalis and $P$. hispanicus. SVL ratio was higher in males than females of all species. Head shape (Table 1a) was more pointed (i.e. lower head shape values) in P. edwardsianus, whereas no differences existed between $P$. hispanicus and $P$. occidentalis. In all species, females showed more pointed heads than males. Snout shape did not differ between species but significantly differed between sexes, being more pointed (i.e. lower snout shape values) in females than in males of the three species. The number of collar scales was higher in P. hispanicus than in the other two species, between which no significant differences existed. Sexes did not significantly differ for this trait. Relative anal scale width was larger in P. occidentalis than in P. edwardsianus but was not larger than in P. hispanicus. In all species, females had significantly smaller anal scales than males.

Hue and saturation of the background colour significantly differed between species (Table 3a). In $P$. edwardsianus, background hue was higher (i.e. more yellow) and saturation lower (i.e. greyer) than in $P$. 
occidentalis. No differences were found between $P$. hispanicus and the other two species. Background brightness did not significantly differ among species and no significant sex differences existed in background hue, saturation, and brightness. Dorsal colour PC1 was higher in P. hispanicus than in P. edwardsianus and $P$. occidentalis, between which no differences existed, indicating that $P$. hispanicus showed lighter dorsal transverse and longitudinal lines than the other two species. Independent of the species, males showed higher dorsal PC1 values than females. Dorsal colour PC2 was higher (i.e. white longitudinal lines were less white and saturated) in P. edwardsianus than in $P$. occidentalis while no significant differences existed between these two species and P. hispanicus. Dorsal colour PC2 was not significantly different between sexes. The dorsal pattern index was higher in P. occidentalis than in P. edwardsianus, indicating that the dorsal pattern was more reticulated in the former species (Fig. S1). Males of all species showed more reticulated dorsal patterns than females. Significant differences existed between species in the proportion of dorsal black colour, although such differences were only marginally significant after adjusting for multiple testing. Thus, the proportion of black colour tended to be higher in $P$. occidentalis compared to the other species (Table 3). Independent of the species, black colour proportion was higher in males than in females. No differences in the proportion of white colour existed between species or sexes. Dorsal lines in $P$. edwardsianus were significantly thicker than in P. occidentalis and tended to be thicker than in P. hispanicus. In this latter species, dorsal lines tended to be thicker than in $P$. occidentalis. No sex difference existed for the dorsal line thickness.

Sexual dimorphism differed between species as revealed by significant species $\times$ sex interactions in Table 2 and 3. Females were heavier than males in $P$. hispanicus and P. occidentalis but not in P. edwardsianus (Table 4). Post-hoc analyses further showed that female body mass differed between species (Table 2 ) whereas no significant interspecific differences existed for males $\left(t_{182}<2.01, P>0.09\right)$. The number of ventral scales was significantly larger in females than in males of all species (Table 4). However, sexual dimorphism was more marked in $P$. hispanicus and $P$. occidentalis than in $P$. edwardsianus, given that females of the first two species showed a higher number of ventral scales than P. edwardsianus females (Table 2) whereas interspecific males did not differ in this trait $\left(t_{182}<1.62, P>0.11\right)$.
The number of ocelli was higher in males than in females of $P$. edwardsianus, whereas no significant differences existed between sexes in $P$. occidentalis and $P$. hispanicus (Table 4). In P. occidentalis, males and females showed numerous ocelli, presenting as many as $P$. edwardsianus males $\left(t_{182}<0.22, P>0.82\right)$. In contrast, $P$. hispanicus males and females showed a reduced number of ocelli, with males showing fewer ocelli than males of the other species $\left(t_{182}>4.04, P<\right.$ 0.01 ), and females showing as few as P.edwardsianus females (Table 3). The extent of the nuptial colouration significantly differed between sexes in P. occidentalis and P. hispanicus but not in P.edwardsianus (Table 4), where it was significantly less extended than in the other two species (Table 3). Neck hue was sexually dimorphic in all species although sex differences were less pronounced in $P$. edwardsianus than in $P$. occidentalis and P. hispanicus (Table 3-4). Neck brightness was sexually dimorphic only in $P$. occidentalis but not in the other two species (Table 4). Neck saturation was different between species and sexes but no significant species $\times$ sex interaction was found. Necks of Psammodromus occidentalis were more saturated than necks of P. hispanicus and P. edwardsianus, between which were found no differences in this trait. Independently of the species, males showed less saturated necks than females.

Ventral colour PC2 was significantly lower in $P$. hispanicus males than in $P$. hispanicus females, whereas no significant differences between sexes were observed in P. edwardsianus and P. occidentalis (Table 4). Among species, $P$. hispanicus females showed higher values (i.e. showed brighter ventral colours) than females belonging to the other two species (Table 3) whereas $P$. occidentalis males showed significantly higher values for ventral colouration PC2 than the other two species $\left(t_{182}>2.60, P<0.03\right)$. Ventral colour PC1 and PC3 were significantly different between sexes but not between species. Males had lower values in the ventral colour PC1 and higher values in the ventral colour PC3 (i.e. more yellow and saturated bellies) than females.

Differences between northern and southern populations of $\mathrm{P}$. edwardsianus

The PERM-MANOVA revealed significant differences between northern and southern P. edwardsianus populations $\left(F_{1,96}=5.17, P=0.001\right)$, between sexes $\left(F_{1,96}=\right.$ 9.82, $P=0.001)$, but no significant interaction between sex and geographic location $\left(F_{1,96}=1.23, P=0.2\right)$. The 


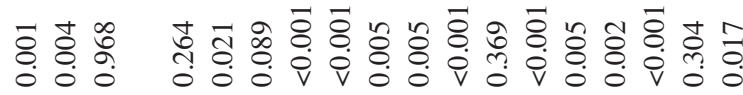

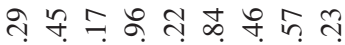

ชำ ๆ $\begin{array}{lllll}\| & \| & \| & \| & \|\end{array}$

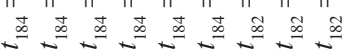
m $m$

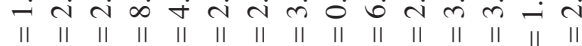

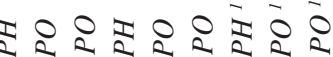

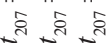

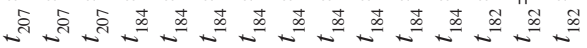
$\check{y} \tilde{y} \check{z} \tilde{z} \check{z} \tilde{z} \check{z}$

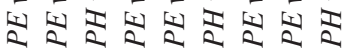

चに\&

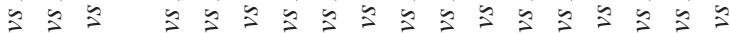

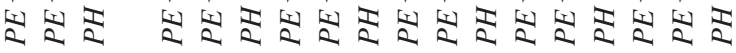

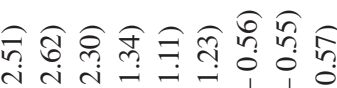

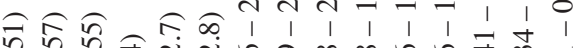

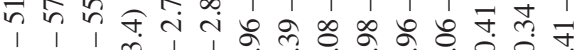

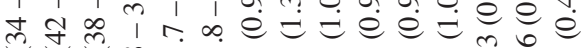

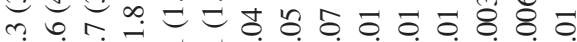

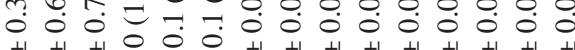

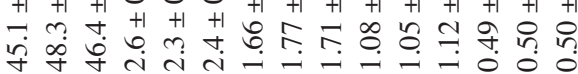

\section{ลิ}

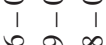

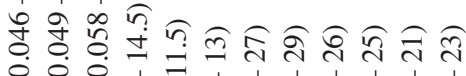

e e e $1=1111111$ की

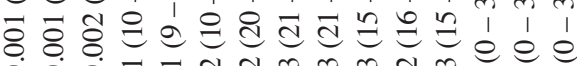

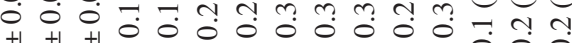

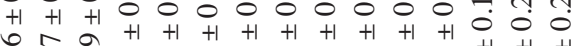

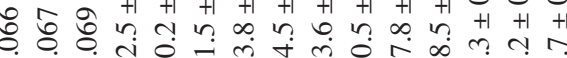

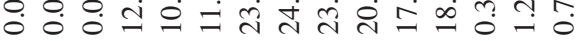

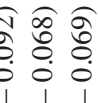

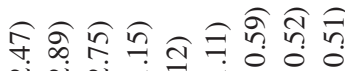

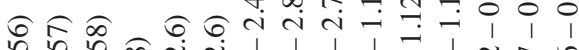

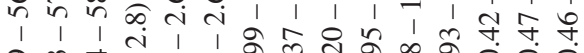

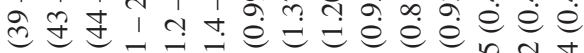

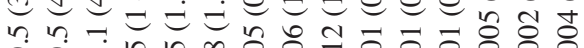

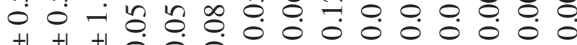

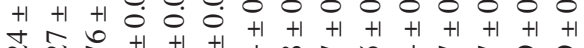
तิ

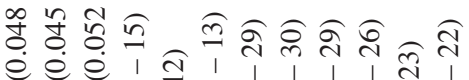

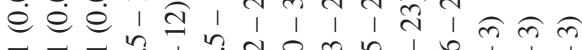

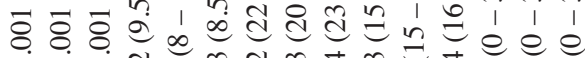
$000 \%$ $+1+1+10000000$

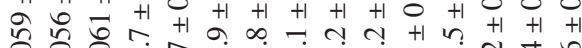

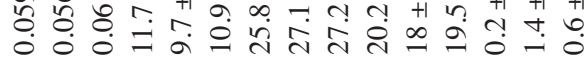

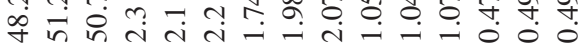

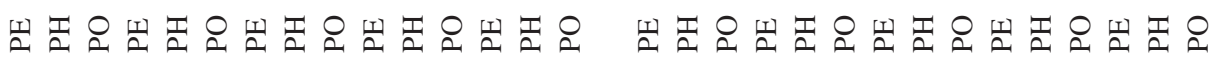

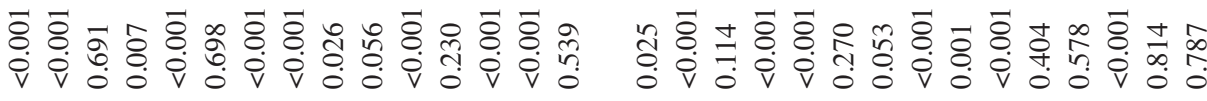

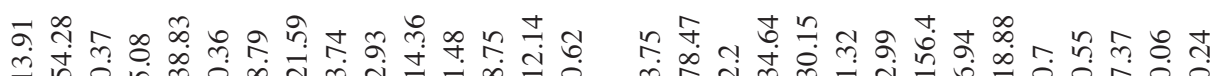
mं山ें

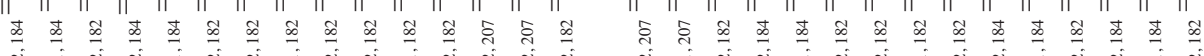

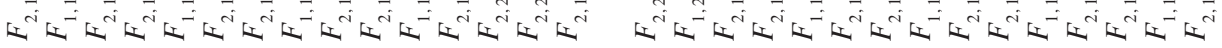

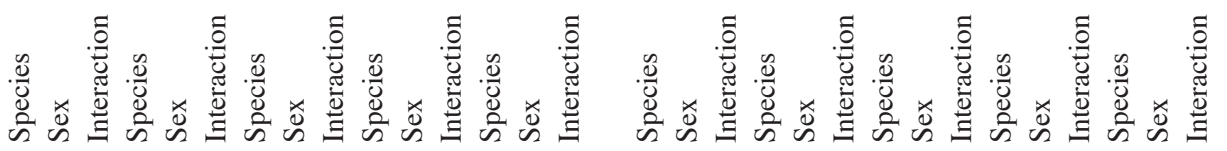




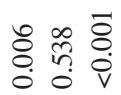

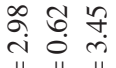

$\underline{\underline{D}} \underline{\underline{D}}$

¿̇o

$\underline{y} \check{y}$

这这空
言言言高

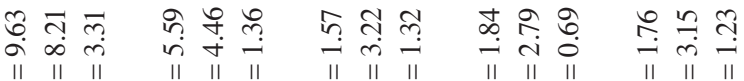

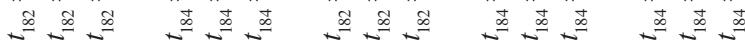

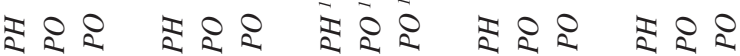

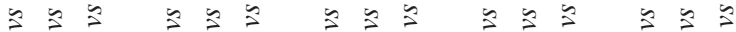

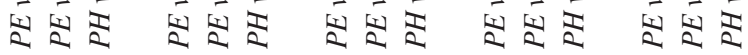

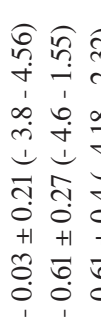

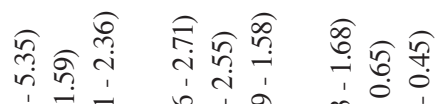

0.100

mi

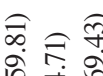

i.

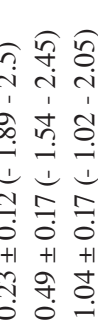

के $\dot{0}$

งิ

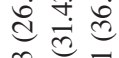

bु

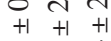

का

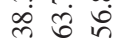

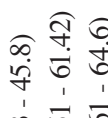

m.

वे ป

证

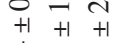

寸 $\bar{\sigma}$

สิษ

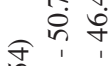

भु

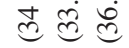

零 $n$

00

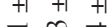

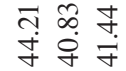

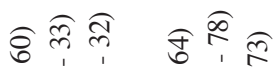

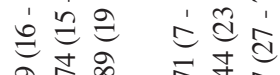

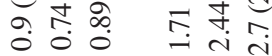

$+1+1+1+1$

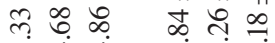

㐫过 宑字

तु

ปั่ ปิ

$\begin{array}{lll}1 & 0 \\ 0 & +1 & 0 \\ 0 & +1\end{array}$

लं चु ले में

i.

(i)

สิ

동

夺

in

भे

in

ते ले ले

m.

e लं

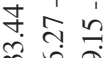

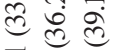

ज. लํ.

$\begin{array}{lll}1 & 0 \\ 0 & 0 & 0 \\ +1 & 0 & 0 \\ 0 & +1\end{array}$

न :

$\begin{array}{lll}+1 & +1 & +1 \\ 2 & +1 & +1\end{array}$

กै

तo

$+\frac{1}{+1}+1$

곤

$+100$

ते ठे :े

$\infty+\infty$

oे tr to

के

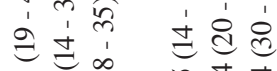

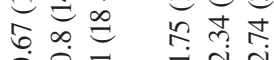

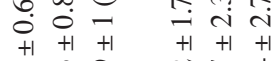

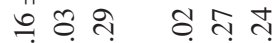

लिं क्षे

तें

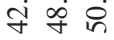

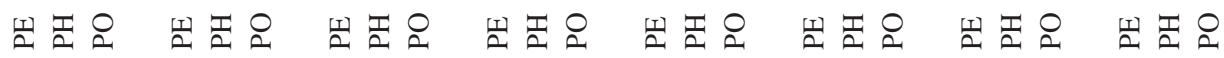

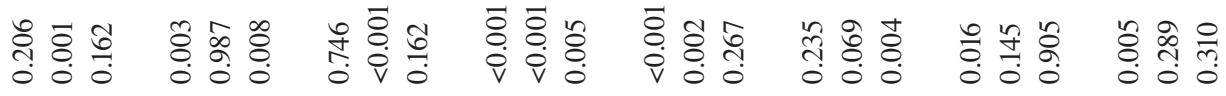

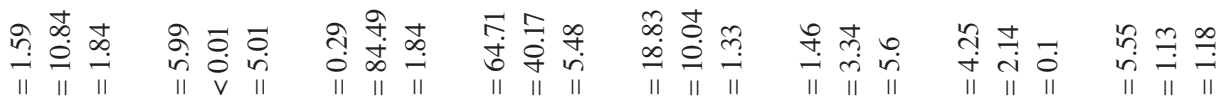

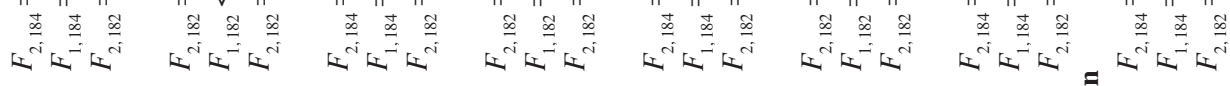

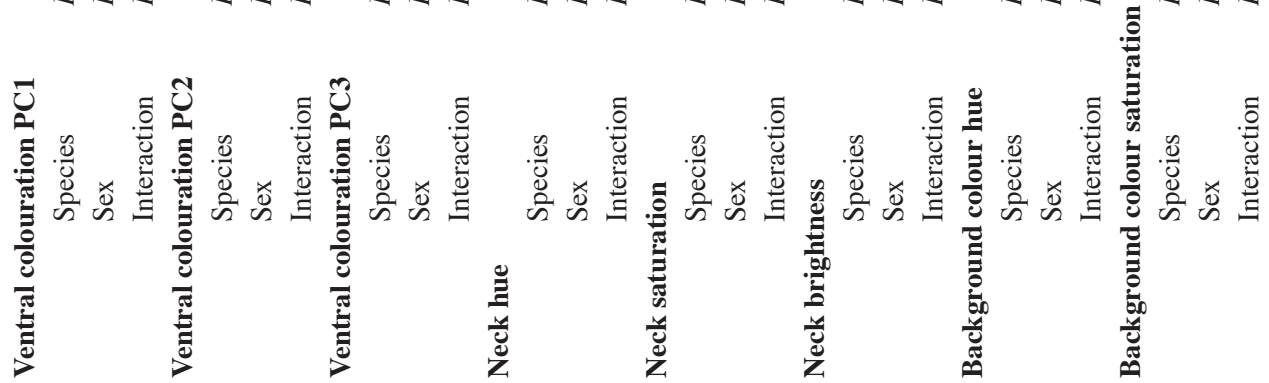




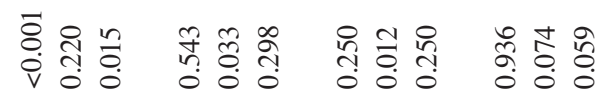

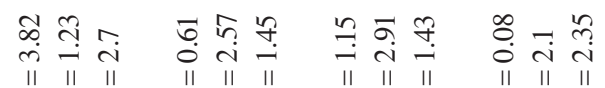

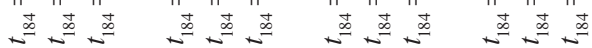

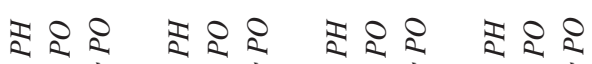

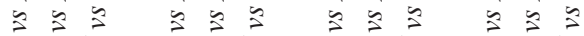

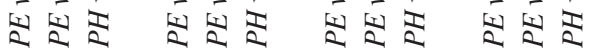

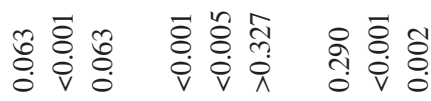

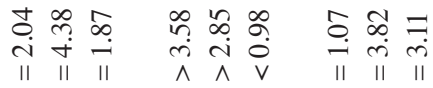

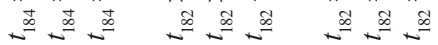

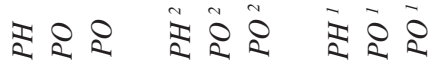
$\check{z} \check{y} \check{z} \check{z} \check{z}$

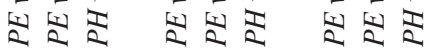

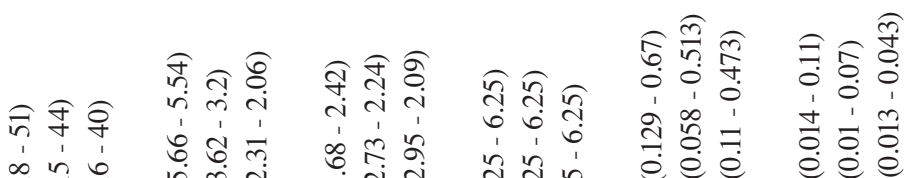

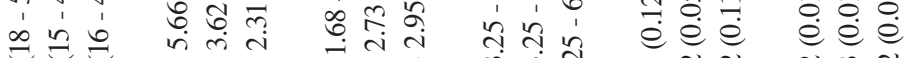

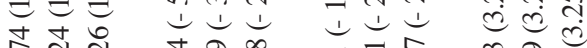

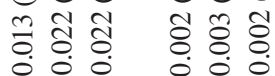

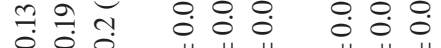

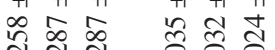

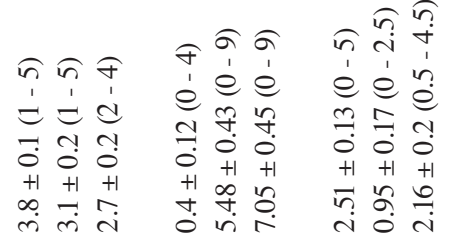

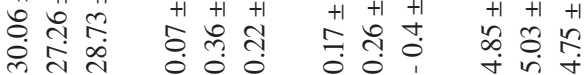

त్र

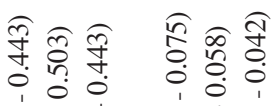

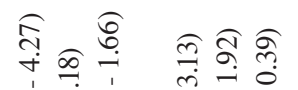

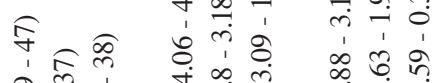

สิธิูล

范实

i 4 i

0

กุ่

e é

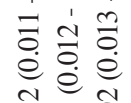

लृ

ปิ

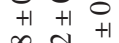

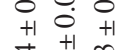

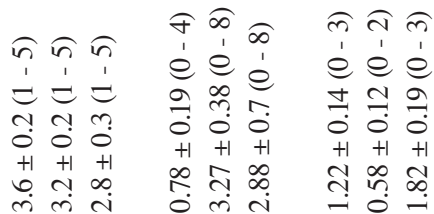

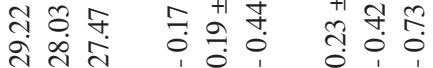

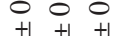

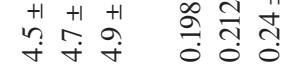

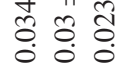

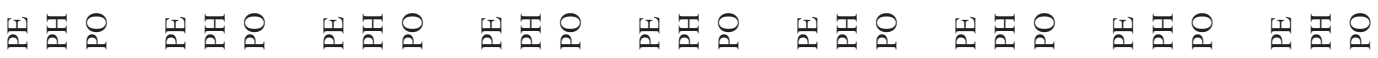

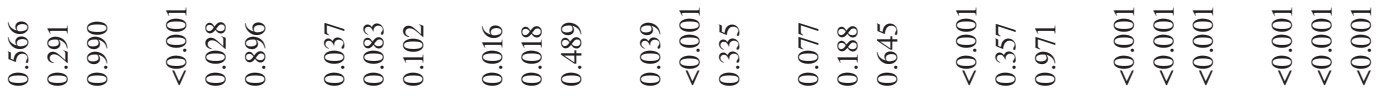

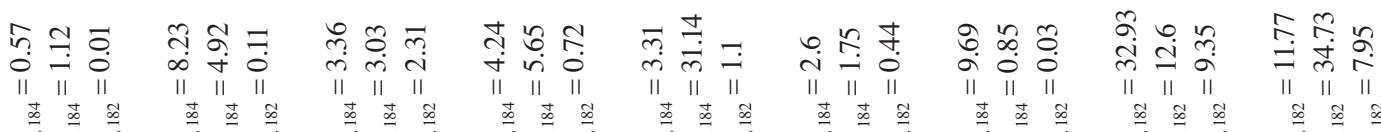

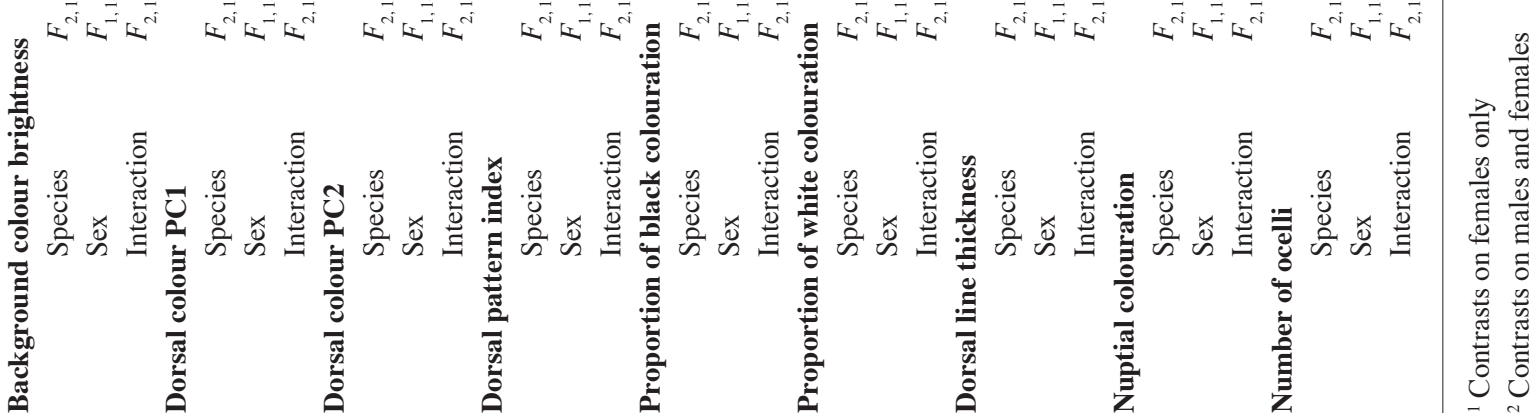


Table 4. Differences in sexual dimorphism among $P$. edwardsianus, $P$. hispanicus, and P. occidentalis. Positive and negative $t$ values indicate that sexual dimorphism is biased toward males and females, respectively. Statistical significance (after corrections for multiple testing) contrasts are indicated with asterisks (*P $P 0.05$, ** $P \leq 0.01$, *** $P \leq 0.001)$.
Fig. 4. Plot of first (LDF1) and second (LDF2) linear discriminant function scores of the discriminant analysis on males and females from northern and southern populations of $P$. edwardsianus. LDF1 allowed distinguishing between males (filled symbols) and females (open symbols) and LDF2 between northern (circles) and southern (squares) populations of $P$. edwardsianus.

\begin{tabular}{llll} 
& P.edwardsianus & P. hispanicus & P.occidentalis \\
\hline Body mass & $t_{182}=-1.22$ & $t_{182}=-2.70^{*}$ & $t_{182}=-3.65^{* *}$ \\
Ventral scale rows & $t_{182}=-6.83^{*}$ & $t_{182}=-7.58^{* *}$ & $t_{182}=-7.75^{* *}$ \\
Number of oceli & $t_{182}=8.60^{* * *}$ & $t_{182}=1.98$ & $t_{182}=1.88$ \\
Nuptial colouration & $t_{182}=-1.34$ & $t_{182}=3.18^{*}$ & $t_{182}=2.72^{*}$ \\
Neck hue & $t_{182}=3.48^{* *}$ & $t_{182}=2.72^{*}$ & $t_{182}=5.04^{* *}$ \\
Neck brightness & $t_{182}=1.83$ & $t_{182}=-1.26$ & $t_{182}=-2.53^{*}$ \\
Ventral colouration PC2 & $t_{182}=0.68$ & $t_{182}=-2.91 *$ & $t_{182}=1.41$
\end{tabular}

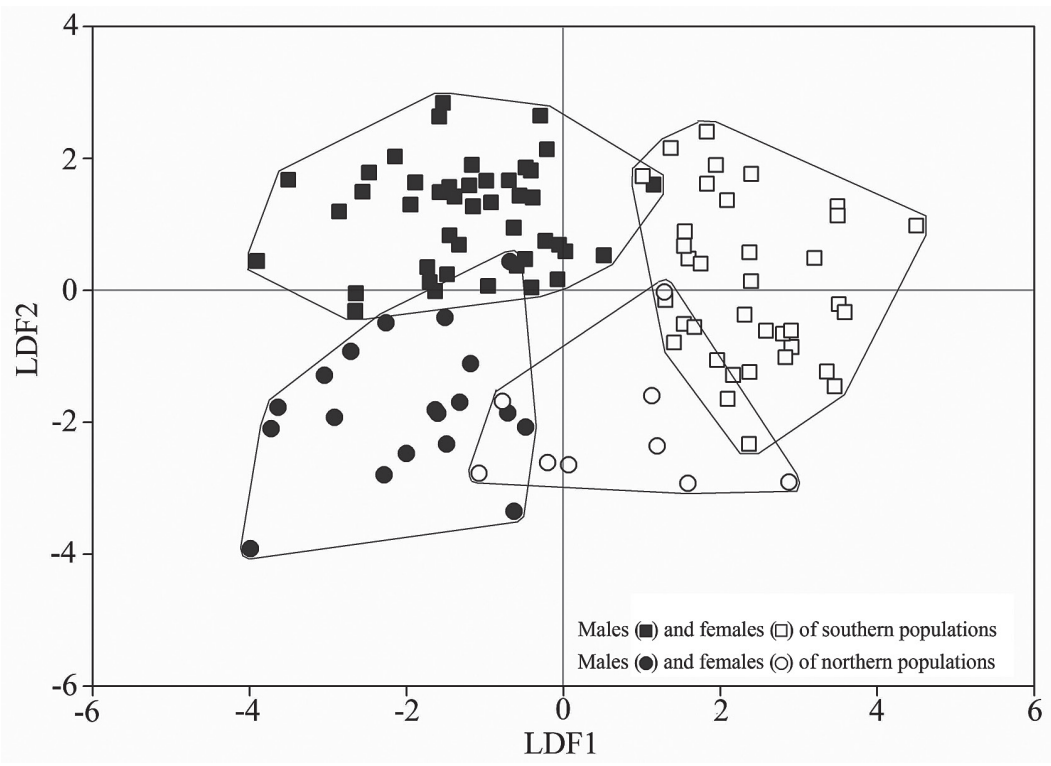

LDF analysis yielded three discriminant functions (Table S4). LDF1 (65\% of the explained variance) reflected the number of ocelli, SVL, SVL ratio, and the number of ventral scales and it separated males from females (Fig. 4). LDF2 (29.9\% of the explained variance) separated northern and southern populations of P. edwardsianus and it mainly reflected the number of throat scales and dorsal colour PC1 (Fig. 4).

Posterior univariate ANOVAs showed that northern populations had fewer throat scales (northern populations: $19.9 \pm 0.2$ scales, southern populations: $21.7 \pm 0.2$ scales, $F_{1,97}=5.72, P=0.019$ ), higher dorsal PC1 values (northern populations: $0.41 \pm 0.2$, southern populations: $-1.53 \pm 0.3, F_{1,97}=10.39, P=$ 0.002 ), and a greener neck colouration (northern populations: $38.46 \pm 0.81^{\circ}$, southern populations: $31.99 \pm$ $\left.1.45^{\circ}, F_{1,97}=5.72, P=0.019\right)$ than southern populations. Additionally, females had more ventral scales than males in northern populations (sex $\times$ geographic location: $F_{1,96}=4.34, P=0.039$, females: $26.03 \pm 0.21$ rows, males: $23.03 \pm 0.21$ rows, $t_{96}=7.41, P<0.0001$ ), but no significant sex differences existed in southern populations (females: $24.89 \pm 0.39$ rows, males: 23.84 $\left.\pm 0.31, t_{96}=1.67, P=0.098\right)$.

\section{Key for the three Psammodromus species}

Psammodromus edwardsianus can be distinguished from the other two species by the presence of a supralabial scale below the subocular scale (see Appendix). Since none of the measured traits allowed for unequivocal distinction between $P$. hispanicus and $P$. occidentalis we ran an additional discriminant analysis based on four easy-to-measure variables; the number of femoral pores, the number of ocelli, the relative anal scale width, and the number of throat scales (see Appendix and Table 1a). Crossvalidation showed that the derived LDFs correctly attributed $89 \%$ of P. hispanicus and $79.5 \%$ of P. occidentalis individuals. The percentage of males and females correctly attributed to these species was $85 \%$ and $86 \%$, respectively. 


\section{Discussion}

\section{Phenotypic differentiation}

Recent molecular studies in Spanish sand racers demonstrated the existence of three genetically differentiated lineages that are now recognized as distinct species (Fitze et al. 2011, 2012). We show that these three species, P. hispanicus, P. edwardsianus, and $P$. occidentalis exhibit substantial differentiation in phenotypic traits and in the degree of sexual dimorphism. As first pointed out by Boulenger (1921), the presence of a supralabial scale below the subocular scale is a good trait to categorically differentiate P. edwardsianus from P. hispanicus and P. occidentalis, whose subocular scale directly touches the mouth. The presence of this scale and the relative position of the subocular scale in relation to the mouth are also accurate diagnostic traits in other genera of the family Lacertidae (e.g. Acanthodactylus; Bons and Geniez, 1995; Harris and Arnold, 2000). However, this scale is absent and the subocular scale always touches the mouth in other species of the genus Psammodromus and in the sister genus Gallotia, indicating that the presence of this scale in P. edwardsianus is unique and derived within the entire subfamily Gallotiinae (Salvador, 1998; Hernández et al., 2000; Galewski et al., 2001). As revealed by the discriminant function analysis, P. edwardsianus can be also distinguished by a higher number of femoral pores and throat scales, and by a less extended nuptial colouration and a less green and less saturated neck colour. In addition, P. edwardsianus presents a smaller SVL, a higher SVL ratio (i.e. a larger relative tail length), and a more pointed head. Psammodromus hispanicus and P. occidentalis could not be distinguished on the basis of a single qualitative trait. However, discriminant functions allowed successful discrimination between the two species $(\sim 80 \%)$. Main differences between $P$. hispanicus and $P$. occidentalis were observed in the number of femoral pores, throat scales, and collar scales, which were smaller in the former species. Further, P. hispanicus showed fewer ocelli than $P$. occidentalis and greener and more saturated neck colourations.

The observed phenotypic differentiation may indicate important differences in performance and behaviour (van Damme et al., 1998). For instance, between species differences in SVL have been observed to result in differences in sprint performance (Losos, 1990; Bauwens et al., 1995), home range (Turner et al., 1969;
Perry and Garland, 2002), thermoregulation, and daily activity patterns (Stevenson, 1985). The smaller SVL in P. edwardsianus may therefore indicate that this species may differ from other Spanish sand racers in some of the above-mentioned features. The more pointed head shape of P. edwardsianus may be associated with shorter bite cycles and reduced prey processing times in contrast to P. hispanicus and P. occidentalis (Verwaijen and van Damme, 2007). Altogether, the phenotypic differences here determined may suggest that distinct selective pressures act on Spanish sand racer species (Losos et al., 1997). Fitze et al. (2011) showed that the three species occupy different ecological niches (those of P. occidentalis and P.edwardsianus are more similar than that of $P$. hispanicus), but found no congruent association between niche differentiation and variation in morphological traits. Other ecological factors than those considered in Fitze et al. (2011) (18 climatic, one topographic and two vegetation index variables) may underlie phenotypic differentiation within Spanish sand racers. For instance, differences in selective pressures derived from community structure (i.e. predation, competitive interactions with other species, and prey spectra) may also result in species differentiation in body size (Blomberg and Shine, 2000), shape (Verwaijen and van Damme, 2007), and colouration (Endler, 1983; Forsman and Appelqvist, 1998).

Psammodromus edwardsianus exhibited substantial phenotypic variation that corresponds to the northsouth genetic structure reported by Fitze et al. (2011). Northern populations exhibited a lower number of throat scales, greener necks, and lighter dorsal colouration. Additionally, females in northern but not in southern populations were larger than males. Such geographic variation in phenotypic traits may be the consequence of postglacial range expansion during which P.edwardsianus may have confronted changing environmental conditions and, hence, different selective pressures as the species expanded toward the north of the Iberian Peninsula (Hewitt, 1996, 1999; Fitze et al., 2011). Similar north-south patterns of phenotypic variation have been reported in other animal species of the Iberian Peninsula (e.g. Alexandrino et $a l ., 2007)$. Given the limited number of individuals captured in southern populations of P.occidentalis, we could not test whether geographic variation in phenotypic traits also exists within $P$. occidentalis. Such variation is expected given the observed north-south differentiation observed within P. edwardsianus, and it deserves further attention. 


\section{Sexual dimorphism}

Strong sexual dimorphism was observed in body measures, scalation traits, colour pattern, and colour traits in all species. We found that females were larger and heavier than males in P. hispanicus and P.occidentalis. Female-biased sexual size dimorphism is usually attributed to selective pressures favouring larger and, hence, more fecund females (Shine, 1989). Selection for female fecundity may be more important in species where small female body size strongly constrains egg carrying capacity (Maritz and Alexander, 2011). Similar selective pressures are likely to occur in Spanish sand racers, which are among the smallest species of the subfamily Gallotiinae. Moreover, larger species of the subfamily Gallotiinae commonly exhibit male-biased size dimorphism (Herrel et al., 1999; Hernández et al., 2000; Molina-Borja, 2003), which may further support this hypothesis. In P. edwardsianus, sexual size dimorphism was less marked given that body mass did not differ between sexes and that SVL was only different between males and females of northern but not of southern populations. Different, non-mutually exclusive hypotheses may underlie relaxed sexual dimorphism in P. edwardsianus. Enlarged female body size is known to impair locomotion and, in circumstances of high predation risk, such impairment may counteract potential fitness gains of enlarged body size (Seigel et al., 1987; Sinervo et al., 1991). In addition to body size enlargement, selection may favour other high-fecundity strategies (Sinervo et al., 2000). Thus, in certain circumstances, selection may favour small females that lay many clutches of few eggs instead of large females that lay many eggs in one single clutch. Both hypotheses may be supported in P.edwardsianus. First, $P$. edwardsianus shows a longer annual activity cycle, which may allow it to lay more than one clutch per year (Carretero and Llorente, 1991b). Second, it lives in more open habitats than, at least, P. occidentalis (Fitze et al., 2011), which may entail a higher predation risk (Carrascal et al., 1989).

The degree of sexual colour dimorphism differed among species in traits that may be under sexual selection (Diaz, 1992; Salvador and Veiga, 2008). Nuptial colouration was highly dimorphic in P. hispanicus and P. occidentalis but not in P.edwardsianus, where it was almost absent. In contrast, the number of ocelli was sexually dimorphic in P.edwardsianus but not in P. hispanicus and $P$. occidentalis. In Spanish sand racers, nuptial colouration and ocelli may play an important role in intra- and intersexual selection, as observed in the sister species $P$. algirus (Linnaeus, 1758) (Martín and Forsman, 1999; Salvador and Veiga, 2001, 2008). The observed differences suggest that the mechanisms governing male-male interactions as well as female mate choice may differ among Spanish sand racer species. Such differences may further impose a barrier to reproduction, preventing gene flow in a scenario of secondary contact among Spanish sand racers (West-Eberhard, 1983; Jiggins et al., 2001). In line with these findings, we found important differences in the number of femoral pores, which may indicate that chemical communication strategies or the relative importance of chemical scent marks for communication may also differ among species (Martín and López, 2000; López and Martín, 2005). Altogether, these findings suggest that different evolutionary forces underlie visual and chemical signalling in Spanish sand racer species, which makes this species group a suitable model to test distinct evolutionary scenarios related with animal signalling and speciation (Maan and Seehausen, 2011).

The data presented here indicate that the degree of phenotypic differentiation is higher between P. edwardsianus and the other Spanish sand racers than between $P$. hispanicus and P.occidentalis. This pattern suggests that the degree of phenotypic differentiation is not correlated with genetic distances in Spanish sand racers, given that $P$. edwardsianus is genetically closer to $P$. hispanicus than to $P$. occidentalis, which diverged from the common ancestor of P. edwardsianus and P. hispanicus. Similarly, phenotypic differentiation was not correlated with inferred ecological niches since $P$. occidentalis and P. edwardsianus showed more similar ecological niches than P. hispanicus. However, this pattern is in line with previous morphological descriptions based on a lower number of traits and where differences between sexes were not considered, which support the robustness of our findings (Fitze et al., 2011). Comparisons among closely related groups often obscure the predicted association between phenotypic and genetic variation, given that differences in other determinant factors (e.g. ecology or behaviour) may strongly increase phenotypic variability (Wayne and O'Brien, 1986; Hackett and Rosenberg, 1990). Differences in the degree of sexual dimorphism suggest that substantial differences in reproductive and sexual behaviour may exist among species, which help to explain why phenotypic and genetic distances are uncoupled within Spanish sand racers. The key to Spanish sand racer species provided here allows field and experimental studies to be conducted that are necessary in order to completely understand the evolutionary mechanisms leading to 
speciation in this group of animals, as well as helping in the conservation management of these species.

\section{Acknowledgements}

We thank R. Zardoya and R. Early for attentive comments and discussion, two anonymous reviewers for constructive comments on the manuscript, B. Pera, G. Pérez i de Lanuza, J. M. Delgado and T. Ponce for field assistance, M. García-París, J. Mellado, G. A. Llorente, F. Palacios, and J. M. Pleguezuelos for indicating locations, the Asociación Herpetológica Española for providing us with the data gathered for the Spanish Atlas of Reptiles and Amphibians. Ana C. Andreu, A. M. Llorente, S. Bañuls and I. R. Maudo for helping with the permits and logistics at the Doñana National park. The capture and handling of lizards was conducted under the licenses provided by Junta de Andalucía, Gobierno de Aragón, Junta de Castilla y León, Junta de Comunidades de Castilla-La Mancha, Generalitat de Catalunya, Junta de Extremadura, Xunta de Galicia, Comunidad de Madrid, Gobierno de Navarra, Generalitat Valenciana, Parque Natural de l'Albufera, Parque Natural del Delta del Ebro, Parque Nacional de Doñana, and Gobierno de España. L.M.S.J. was supported by a PhD grant (I3P060501) from the Consejo Superior de Investigaciones Científicas (CSIC) and the European Social Fund, V. G.-J. by a PhD grant from the Spanish Ministry of Education and Science (FPU-AP2006-01678) and P.S. Fitze by a grant from the Spanish Ministry of Education and Science (RYC-2003-006136). Project costs were financed by the Comunidad de Madrid (200530M090 to PSF) and the Swiss National Science Foundation (PPOOP3_128375).

\section{References}

Alexandrino J, Teixeira J, Arntzen JW, Ferrand N. 2007. Historical biogeography and conservation of the golden-striped salamander (Chioglossa lusitanica) in Northwestern Iberia: Integrating ecological, phenotypic and phylogeographic data. Pp. 189-205 in: S Weiss and N Ferrand, eds, Phylogeography of Southern European Refugia. Dordrecht: Springer.

Anderson M. 1994. Sexual selection. Princeton: Princeton University Press.

Anderson MJ. 2001. A new method for non-parametric multivariate analysis of variance. Austral Ecology 26: 32-46. doi: 10.1111/j.1442-9993.2001.01070.pp.x.

Bauwens D, Garland TJ, Castilla AM, van Damme R. 1995. Evolution of sprint speed in lacertid lizards: Morphological, physiological and behavioral covariation. Evolution 49: 848-863.

Blasco M. 1974. Contribución al conocimiento de los lacértidos de Andalucía. PhD thesis Universidad de Granada, Granada.

Blomberg SP, Shine R. 2000. Size-based predation by kookaburras (Dacelo novaeguineae) on lizards (Eulamprus tympanum: Scincidae): What determines prey vulnerability? Behavioral Ecology and Sociobiology 48: 484-489. doi: $10.1007 / \mathrm{s} 002650000260$.

Bons J, Geniez P. 1995. Contribution to the systematics of the lizard Acanthodactylus erythrurus (Sauria, Lacertidae) in Morocco. Herpetological Journal 5: 271-280.
Boulenger GA. 1921. Monograph of the Lacertidae. London: British Museum.

Carranza S, Harris DJ, Arnold EN, Batista V, Gonzalez de la Vega JP. 2006. Phylogeography of the lacertid lizard, Psammodromus algirus, in Iberia and across the Strait of Gibraltar. Journal of Biogeography 33: 1279-1288. doi: 10.1111/j.1365-2699.2006.01491.x.

Carrascal LM, Diaz JA, Cano C. 1989. Habitat selection in Iberian Psammodromus species along a Mediterranean successional gradient. Amphibia-Reptilia 10: 231-242. doi: 10.1163/156853889X00403.

Carretero MA, Llorente GA. 1991a. Alimentación de Psammodromus hispanicus en un arenal costero del noreste ibérico. Revista Española de Herpetología 6: 31-44.

Carretero MA, Llorente GA. 1991b. Reproducción de Psammodromus hispanicus en una arenal costero del nordeste ibérico. Amphibia-Reptilia 12: 395-408.

Damme R van, Aerts P, Vanhooydonck B. 1998. Variation in morphology, gait characteristics and speed of locomotion in two populations of lizards. Biological Journal of the Linnean Society 63: 409-427. doi: 10.1111/j.1095-8312.1998.tb01526.x.

Diaz JA. 1992. Breeding coloration, mating opportunities, activity, and survival in the lacertid lizard Psammodromus algirus. Canadian journal of zoology 71: 1104-1110. doi: 10.1139/z93-150.

Dugès A. 1829. Mémoir sur les espèces indigènes du genre Lacerta. Annales des Sciences Naturelles 16: 337-339.

Endler JA. 1983. Natural and sexual selection on color patterns in poeciliid fishes. Environmental Biology of Fishes 9: 173190. doi: $10.1007 /$ bf00690861.

Fitze PS, Richner H. 2002. Differential effects of a parasite on ornamental structures based on melanins and carotenoids. Behavioral Ecology 13: 401-407. doi: 10.1093/beheco/13.3.401.

Fitze PS, Gonzalez-Jimena V, San-Jose LM, San Mauro D, Aragon P, Suarez T, Zardoya R. 2011. Integrative analyses of speciation and divergence in Psammodromus hispanicus (Squamata: Lacertidae). BMC Evolutionary Biology 11: 347. doi:10.1186/1471-2148-11-347.

Fitze PS, Gonzalez-Jimena V, San-Jose LM, San Mauro D, Zardoya R. 2012. A new species of sand racer, Psammodromus (Squamata: Lacertidae), from the Western Iberian Peninsula. Zootaxa 3205: 41-52.

Fitzinger LI. 1826. Neue classification der reptilien nach ihren natürlichen verwandtschaften. Vienna: Heubner JG.

Forsman A, Appelqvist S. 1998. Visual predators impose correlational selection on prey color pattern and behavior. Behavioral Ecology 9: 409-413. doi: 10.1093/beheco/9.4.409.

Galewski T, Crochet P-A, Geniez P. 2001. Etude morphometrique des Psammodromus endemiques du Maghreb: Psammodromus blanci Lataste 1880, Psammodromus microdactylus Boettger, 1881. Mémoire d'initation à la recherche. Université de Montperllier II.

Hackett SJ, Rosenberg KV. 1990. Comparison of phenotypic and genetic differentiation in South American antwrens (Formicariidae). The Auk 107: 473-489.

Harris DJ, Arnold EN. 2000. Elucidation of the relationships of spiny-footed lizards, Acanthodactylus spp. (Reptilia: Lacertidae) using mitochondrial DNA sequence, with comments on their biogeography and evolution. Journal of Zoology 252: 351-362. doi: 10.1111/j.1469-7998.2000.tb00630.x. 
Hellmich W. 1962. Reptiles and amphibians of Europe. London: Blandford Press.

Hernández E, Nogales M, Martín A. 2000. Discovery of a new lizard in the canary islands, with a multivariate analysis of Gallotia (Reptilia: Lacertidae). Herpetologica 56: 63-76.

Herrel A, Spithoven L, van Damme R, De Vree F. 1999. Sexual dimorphism of head size in Gallotia galloti: Testing the niche divergence hypothesis by functional analyses. Functional Ecology 13: 289-297. doi: 10.1046/j.1365-2435.1999. 00305.x.

Hewitt GM. 1996. Some genetic consequences of ice ages, and their role in divergence and speciation. Biological Journal of the Linnean Society 58: 247-276. doi: 10.1111/j.10958312.1996.tb01434.x.

Hewitt GM. 1999. Post-glacial re-colonization of European biota. Biological Journal of the Linnean Society 68: 87-112. doi: 10.1111/j.1095-8312.1999.tb01160.x.

Hochberg Y. 1988. A sharper Bonferroni procedure for multiple tests of significance. Biometrika 75: 800-802. doi: 10.1093/ biomet/75.4.800.

Jiggins CD, Naisbit RE, Coe RL, Mallet J. 2001. Reproductive isolation caused by colour pattern mimicry. Nature 411: 302-305. doi: 10.1038/35077075.

Lande R. 1981. Models of speciation by sexual selection on polygenic traits. Proceedings of the National Academy of Sciences USA 78: 3721.

Lessells CM, Boag AM. 1987. Unrepeatable repeatabilities: A common mistake. The Auk 104: 116-121.

López P, Martín J. 2005. Female Iberian wall lizards prefer male scents that signal a better cell-mediated immune response. Biology Letters 1: 404-406. doi: 10.1098/rsbl.2005. $\underline{0360 .}$.

Losos JB. 1990. The evolution of form and function: Morphology and locomotor performance in West Indian Anolis lizards. Evolution 44: 1189-1203.

Losos JB, Warheitt KI, Schoener TW. 1997. Adaptive differentiation following experimental island colonization in Anolis lizards. Nature 387: 70-73. doi: 10.1038/387070a0.

Maan ME, Seehausen O. 2011. Ecology, sexual selection and speciation. Ecology Letters 14: 591-602. doi: 10.1111/j.14610248.2011.01606.x.

Maritz B, Alexander GJ. 2011. Morphology, sexual dimorphism, and growth in the smallest viperid, Bitis schneideri (Reptilia: Squamata: Viperidae). Journal of Herpetology 45: 457-462. doi: 10.1670/10-281.1.

Martín J, Forsman A. 1999. Social costs and development of nuptial coloration in male Psammodromus algirus lizards: An experiment. Behavioral Ecology 10: 396-400. doi: 10.1093/beheco/10.4.396.

Martín J, López P. 2000. Chemoreception, symmetry and mate choice in lizards. Proceedings of the Royal Society of London B: Biological Sciences 267: 1265-1269. doi: 10.1098/ rspb.2000.1137.

McArdle BH, Anderson MJ. 2001. Fitting multivariate models to community data: A comment on distance-based redundancy analysis. Ecology 82: 290-297.

Molina-Borja M. 2003. Sexual dimorphism of Gallotia atlantica atlantica and Gallotia atlantica mahoratae (Lacertidae) from the Eastern Canary Islands. Journal of Herpetology 37: 769-772. doi: 10.1670/11-03a.
Perez-Mellado V. 1998. Psammodromus hispanicus Fitzinger, 1826. Pp. 318-326 in: A Salvador, ed., Fauna Iberica. Madrid: Museo Nacional de Ciencias Naturales. CSIC.

Perry G, Garland T. 2002. Lizard home ranges revisited: Effects of sex, body size, diet, habitat, and phylogeny. Ecology 83: 1870-1885. doi: $10.2307 / 3071771$.

Quinn GP, Keough MJ. 2002. Experimental design and data analysis for biologist. Cambridge: Cambridge University Press.

Salvador A. 1998. Reptiles. Pp. 712 in: MA Ramos, ed., Fauna Iberica. Madrid: Museo Nacional de Ciencias Naturales, CSIC.

Salvador A, Veiga JP. 2001. Male traits and pairing success in the lizard Psammodromus algirus. Herpetologica 57: 77-86.

Salvador A, Veiga JP. 2008. A permanent signal related to male pairing success and survival in the lizard Psammodromus algirus. Amphibia-Reptilia 29: 117-120. doi: $10.1163 / 156853808$ 783431488 .

Seigel RA, Huggins MM, Ford NB. 1987. Reduction in locomotor ability as a cost of reproduction in gravid snakes. Oecologia 73: 481-485. doi: 10.1007/bf00379404.

Shine R. 1989. Ecological causes for the evolution of sexual dimorphism: A review of the evidence. The Quarterly Review of Biology 64: 419-461.

Sinervo B, Hedges R, Adolph SC. 1991. Decreased sprint speed as a cost of reproduction in the lizard Sceloporus Occidentalis: Variation among populations. Journal of Experimental Biology 155: 323-336.

Sinervo B, Svensson E, Comendant T. 2000. Density cycles and an offspring quantity and quality game driven by natural selection. Nature 406: 985-988. doi: 10.1038/35023149.

Stevenson RD. 1985. Body size and limits to the daily range of body temperature in terrestrial ectotherms. The American Naturalist 125: 102-117.

Stuart-Fox DM, Moussalli A, Marshall NJ, Owens IPF. 2003. Conspicuous males suffer higher predation risk: Visual modelling and experimental evidence from lizards. Animal Behaviour 66: 541-550. doi: 10.1006/anbe.2003.2235.

Stuart-Fox DM, Ord TJ. 2004. Sexual Selection, natural selection and the evolution of dimorphic coloration and ornamentation in agamid lizards. Proceedings of the Royal Society of London B: Biological Sciences 271: 2249-2255. doi: 10.1098/ rspb.2004.2802.

Turner FB, Jennrich RI, Weintraub JD. 1969. Home ranges and body size of lizards. Ecology 50: 1076-1081.

Venables WN, Ripley BD. 1999. Modern applied statistics with S: Statistics and Computing. New York: Springer.

Verwaijen D, van Damme R. 2007. Does foraging mode mould morphology in lacertid lizards? Journal of Evolutionary Biology 20: 1950-1961. doi: 10.1111/j.1420-9101.2007.01367.x.

Wayne RK, O'Brien SJ. 1986. Empirical demonstration that structural gene and morphometric variation of mandible traits are uncoupled between mouse strains. Journal of Mammalogy 67: 441-449.

West-Eberhard MJ. 1983. Sexual selection, social competition, and speciation. The Quarterly Review of Biology 58: 155-183.

Received: 13 June 2012

Revised and accepted: 11 September 2012

Published online: 3 December 2012

Editor: J.W. Arntzen 


\section{Appendix}

\section{Key to the Spanish sand racers}

1. Presence of a supralabial scale below the subocular scale P. edwardsianus

1'. No supralabial scale below the subocular scale 2

2. Value from $E 1$ greater than value from $E 2$ P. hispanicus

2'. Value from $\mathrm{E} 2$ greater than value from $\mathrm{E} 1$ P. occidentalis

\section{Females:}

$e^{(9.03+(0.13+\text { throat scales }-0.6 \times \text { femoral pores }-0.89 \times \text { ocelli }-91.8 \times \text { relative anal scale width }))}[\mathrm{E} 1]$

$e^{(-21.47+(-0.26 \times \text { throat scales }+1.17 \times \text { femoral pores }+1.73 \times \text { ocelli }+178.2 \times \text { relative anal scale width }))}[\mathrm{E} 2]$

\section{Males:}

$e^{(7.9+(0.06 \times \text { throat scales }-0.86 \times \text { femoral pores }+0.46 \times \text { ocelli }+1.15 \times \text { relative anal scale width })}[\mathrm{E} 1]$

$e^{(-13.9+(-0.08 \times \text { throat scales }+1.21 \times \text { femoral pores }+0.64 \times \text { ocelli }-1.62 \times \text { relative anal scale width }))}$ [E2]

\section{On-line supplementary information (SI)}

S1. Sampled localities and sample size.

$S 2$. Details of the method used for measuring the dorsal pattern

S3. Component loadings of principal component analyses.

$S 4$. Factor loadings from the linear discriminant functions on the three Spanish sand racer species and on northern and southern populations of P. edwardsianus. 
